\title{
El hombre: personaje y autor en la literatura peruana
}

U

N verdadero mosaico de tipos humanos tenía la población peruana a principios del presente siglo. El aceleramiento del cruce y una creciente definición de sus tipos en los últimos 50 años, muestran las dos principales direcciones que toma el proceso del mestizaje: hacia los grupos cholos y hacia los grupos mulatos, con residencia en las regiones de la sierra y de la costa, respectivamente.

Esclareciendo los orígenes y la evolución de nuestro proceso étnico, recordemos que el primer contacto de razas comenzó en la Conquista. Descartada la tesis autoctonista -en lo que se refiere al origen del hombre americano, no a su cultura que es posible considerar "como nacida de la propia tierra" - queda en pie la hipótesis de la ascendencia asiática con raíces mongoloides y polinésicas. Sobre tal raza, secularmente trabajada por el acento cósmico de su residencia, cayó el aluvión de la raza española, perteneciente a la familia ligur o mediterránea, con raíces pirenaica occidental, alpina $\mathrm{y}$ armenoide. Sobre sus cimientos celtas e iberos, bien es sabido, la raza española soportaba materiales fenicios, griegos, cartagineses; aportes romanos; elementos iránicos o arios, bárbaros: germanos, árabes con mezcla berberisca y etiope, aportaciones flamencas, italianas y de gitanos errantes. Este complicado mestizaje, evolucionando en las distintas regiones de España, dió a su vez los frutos diferenciados de andaluces, extremeños, vascos, catalanes.

Los hombres que conquistan y colonizan el Nuevo Mundo traían, de este modo, una tónica regional perfectamente definida, aunque mantuvieran inalterables las características étnicas comunes y fundamentales del mestizaje que les dió origen. Respetando los rasgos 
singulares y solidarios de la raza aborigen en el mapa americano, naturaleza, economía y cultura habían labrado también matices y contrastes en el tipo humano. Los españoles encuentran la gama tipológica de los pueblos serranos y costeños que forman la unidad económico-social del Tahuantisuyo: chibchas, quitus, tallanes, mochicas, quechuas, chibchas, huancas, aymaras, huanucos, caxamalcas, pocras, huaylas, araucanos. Del cruce inicial --varones españoles, hembras indígenas - surge el mestizo. Arquetipos de este primer ayuntamiento son, para el Perú, Garcilaso de la Vega y Almagro el Mozo.

Pronto intervino un nuevo afluente: fue el negro, cazado en Africa, traido entre cadenas con destino de esclavo "para liberar al indio" de sus yugos. En realidad no lo libertó, compartió con él la esclavitud. Indio, blanco y negro se convierten en los elementos precursores de una integración racial que da paso a la nueva familia humana. Tras el choque violento de la Conquista aceléranse las funciones de cruce, asimilación, mezcla y aleaciones. Durante la República entran en acción nuevos afluentes: europeos y asiáticos. Los últimos han logrado producir un nuevo tipo: el injerto, fruto de su cruce con el elemento mestizo existente. El vasto intento de fusión biológica, social y cultural no termina aún, gravemente entorpecido por contradicciones de orden económico, político y espiritual.

El último censo anota 7 millones de habitantes para el Perú. En una estimativa general se puede asignar los siguientes porcientos a los grupos humanos: $80 \%$, indios y cholos $(50 \%$ indios: $3.500 .000-30 \%$ cholos: 2.100 .000$) ; 10 \%$, negros y grupos afines $(700.000) ; 5 \%$, blancos $(350.000) ; 4 \%$, población de la selva $(280.000) ; 1 \%$, asiáticos $(70.000)$. La población está integrada por indios, negros, blancos, asiáticos y los productos del cruce de las razas entre si: cholos (razas blanca e india de costa y sierra); mulatos (razas blanca y negra); zambos (razas negra e india); injertos (razas asiática y mestiza).

La costa es el asiento de blancos, mulatos, zambos e injertos, predominantemente. Aunque residencia de sólo el $22 \%$ de la población total del Perú, esta región alberga el $61 \%$ de la población urbana. El blanco - de ascendencia española o descendiente de la posterior inmigración europea- dirige industrias, bancos, vías de 
comunicación, comercio. Su preponderancia económica gravita en la política e indirectamente sobre la cultura a través de los medios de difusión (prensa, radio, editoriales), de la educación oficial y particular regimentada por el clero o ejercida, caso de la segunda, por las congregaciones religiosas. En Lima y ciudades principales de costa y sierra, el blanco se agrupa en círculos "aristocráticos", basados en privilegios de fortuna, más que en prejuicios raciales, pues la sangre aventurera y renovadora del mestizo ha cruzado sus tónicas inyecciones en los pedigrees más orgullosos. De ahí que cholos o mulatos que arriban a situaciones espectables en la economia, la vida profesional o las letras, alcanzan a codearse familiarmente con la clase dominante; y cholos y mulatos, sin los recursos anteriores, pero que cobran sorpresiva notoriedad pública capitaneando una insurrección armada, llegan a los más altos puestos públicos y circulan homenajeados en los salones del "gran mundo" presidido por los blancos. ${ }^{1}$

El negro retinto no tiene esas oportunidades. $\mathrm{El}$ mismo parece limitarse a su condición subalterna desde la Colonia. No pasaron a la sierra sus padres venidos en los barcos negreros: arraigaron y se multiplicaron en los valles costeños. Como islas de color se sucedían las poblaciones negras a lo largo de la costa, cuando Castilla declaró su libertad en 1868: Tangalá, Talambo, Zana, Facalá, Picsi, Cañete, Chulucanas, Ica. El negro prefirió el llano, al igual de los españoles, y en contradicción a su desdén por el indio, brindó sus simpatías al blanco desde el primer momento. Andando el tiempo los amos blancos buscaron mujeres de color - no indias- para la crianza de sus hijos. (Las "mamas" negras, las ayas de color que recuerdan en sus evocaciones José de la Riva Agüero y Ventura García Calderón.) Y no resistieron la tentación fresca, picante, avasalladora de las esclavas sensuales. A la inversa - desde abajomulatos ardientes y escultóricos rindieron el sexo de las blancas; lances que revelan en dramáticas captaciones Ricardo Palma y Enrique López Albújar. Pero el cruce de las "piezas de ébano" no apresura su ritmo sino cuando el aluvión negro invade los poblados y ciudades - tras su liberación-y se une a los frutos del mestizaje costeño de blanco y aborigen.

Mulatos y zambos preponderan numéricamente, hoy en dia, sobre los núcleos blancos, las concentraciones de cholos serranos en 
los valles, los grupos injertos y los reductos de cholos costeños descendientes de los yungas. Alguien habló por eso de una costa zamba o mulata. $Y$ es que la personalidad de los frutos negroides ha impuesto su sello en muchas manifestaciones de la vida costeña. $\mathrm{El}$ negro no sólo trajo su tipo exótico, la sonrisa melosa, las leyendas maternales, el tranco voluptuoso de sus hembras, la pasión por el color detonante, la lujuria primitiva y dispuesta. Junto al yugo de esclavo importó la magia fetichista, la naturaleza de insurrecto, su tendencia anarquista, el prodigioso sentido musical. No hay en la costa peruana guitarristas de tan admirable digitación o cantores más expresivos y de mayor registro vocal, que zambos y mulatos. Los negros olvidaron voluntariamente su estilo musical y repitieron en el Perú la proeza de adoptar el estilo de sus dominadores para crear nuevos géneros. Así lo hicieron en Cuba, Venezuela, Brasil y Estados Unidos. Son, festejo y tonderos peruanos tienen raíces negras, al igual que la Marinera, hermana de la Cueca, y ambas hijas de la arrebatadora zamba o zambacueca. Nuestro vals criollo, lánguido, dulzón, matizado de caídas, arrastres y floreos, no puede ocultar el dejo mulato de su ritmo ni el verso barroco de la mayor parte de sus letras.

La musicalidad del nègro es cualidad gemela de aquella facundia verbal que a diario observamos en la flexible y melosa labia de sus descendientes. La superabundante energía verbal se gasta en el canto o busca los vertederos de la charla sostenida o la discusión inacabable. Una de sus típicas expresiones es la oratoria pomposa, narrativa o de elogio, discursiva y a veces estética. Fernando Casós fué el ejemplo peruano más perfecto de la oratoria política plástica y caudalosa, avasalladora más que persuasiva. ¿La deslumbradora lujuria verbal de Chocano no tendría algún remoto antecedente de color? Abraham Valdelomar -conjunción de tres razas: india, blanca, negra- canalizó la insolencia mulata a través de sus estilizadas posturas esnobistas; pero no pudo esquivar el amor femenino de cualquier negro por el retoque personal ni el subconsciente anhelo barroco por el rito y la fastuosidad. Ricardo Palma amainó la befa del mulato cerniéndola en el humor sonriente y alusivo de su pulida ironía. No ha surgido aún el poeta de color que traduzca el alma de la raza, al estilo del cubano Nicolás Guillén. Aparte Palma, más que Valdelomar, el relato no tiene autor mulato más representativo 
que Enrique López Albújar. Un autor, además, orgulloso de sus cabeceras negras, al revés de los literatoides sacalagua que acostumbran renegar de sus raíces. Cuando López Albújar me obsequió Matalaché - novela del gallardo mulato que violó, a instancia enamorada de la dueña, el sexo prohibido del ama blanca- puso esta significativa dedicatoria: "Para A. A. L. a quien le ha merecido tan buen juicio este hijo mío, en la Literatura, y abuelo mío en la sangre".

En general, y hasta hoy, mulatos y zambos son actores más que autores en la literatura peruana. Todo el rico folklore costeño - comezado a remover en el norte por $\mathrm{R}$. Paredes y León Barandiarán ( $A$ golpe de arpa) - muestra su oscura y sugestiva presencia en la letra de los cantares, la trama popular de cuentos y refranes, el sacerdocio de los despenadores:-personajes casi desaparecidos que practicaban la eutanasia con enfermos incurables- las hazañas bandoleras, el ejercicio de la brujería, la historia de motines y contrabandos, el anecdotario judicial de raptos y violaciones.

Fernando Romero continúa en este siglo la tarea literaria de introducir y reivindicar al negro en la literatura. Angela Ramos y José Torres de Vidaurre empezaron a traducir la emoción lírica de la zamba limeña y la típica sacalagua del arrabal. El zambo del hampa se exhibe en los cuentos de J. Díez Canseco, Heraldo Falconí Sevilla, Ricardo Alcalde, Fernando Romero. En Panorama hacia el $a l b a$, de José Ferrando, acciona la mulata mórbida y codiciada del lupanar, frente a su macho oscuro y atlético. El brujo negro aparece en $E l$ daño de Camino Calderón. Quien ha realizado el estudio más serio y documentado es el sociólogo Roberto Mac Lean ( $\mathrm{Ne}$ gros en el Perú-Negros en el Nuevo Mundo).

La presencia del hombre de color en el folklore nos está probando tanto su contacto con el pueblo como su posición social dentro de las clases populares. Zambos y mulatos pertenecen en su mayoría al proletariado urbano y campesino. Algunos alcanzan la clase media como empleados, pequeños comerciantes, pequeños industriales, pequeños propietarios, maestros de taller, profesionales, artesanos. Muchas de las características del costeño tienen seguro antecedente en las levaduras raciales del aluvión negro: indolencia, extraversión, volubilidad, amor por la jarana y la política, en- 
tusiasmo explosivo, imaginación viva, locuacidad, sentido de adaptación, tendencia a la improvisación.

Al lado de estos frutos del cruce negro, grandes legiones de cholos serranos comparten vida y trabajos de los valles costeños. Antes formaban una población flotante que tornaba a la sierra apenas terminadas las faenas agrícolas. Poco a poco ha ido arraigando en los campamentos, mal adaptada al clima, al trabajo y a ciertas costumbres de la costa, pero manteniendo intactos sus viejos usos, su música, la indumentaria, el lenguaje amagado de modismos. Y no se curan jamás de la añoranza. Son una especie de modernos mitimaes, ${ }^{2}$ atados inexorablemente a la tieŕa lejana por el vínculo de una ruda y penetrante nostalgia. No han surgido aún ni el poeta ni el cuentista que inscriba en la literatura la vida de esta típica y vigorosa cholada en trasplante. Como no salta el autor que haga la revelación definitiva de paisaje y drama del valle costeño a través de proletarios petroleros, raumadores de algodón, regadores de arroz, cortadores de caña, yanacones y enganchados, trágicos soportes humanos de una industria de gran avance técnico, pero que sigue anclada en el absurdo régimen feudal del trabajo. Sólo existen algunas notas poéticas aisladas ${ }^{3}$ y el peón del valle se empieza a insinuar con Simache (Ortiz Reyes), con Valle algodonero (A. Manco Campos), y débilmente en Rastrojo (M. R. Macedo).

Hay otros núcleos humanos que pueblan campiñas o se agrupan en poblados pescadores al lado de puertos y caletas. Son como los eslabones rotos de la gran cadena humana tendida a lo largo de la costa por las civilizaciones de tallanes, mochicas, chimus, rimacs, nazcas, chibchas. De tórax amplio, rostro cetrino, ojos almendrados, narices afiladas, tienen la estampa clásica que han hecho perdurar huacos y telas de Batán Grande, Pachacamac, Chanchan, Parakas y Nepeña. Persiste la nomenclatura autóctona para los pueblos: Moche, Eten, Huacho, Supe, Monsefú, Sechura, Catacaos, Chicama, Chocope, Sullana, Chimbote, Virú. Pescadores, agricultores, tejedores, mantienen en parte el antiguo régimen comunal de vida y pervive la tradición en las leyendas, supersticiones y cantares; pero el arte nativo ha muerto o se ha eclipsado. Aunque subsisten los caballitos de totora ${ }^{4}$ y la vieja fauna marina, no existe una alfarería que, como la precolombina, haga la reproducción idealizada 
de ellos, y han desaparecido los pescadores de perlas perennizados en tapices y vasijas chimús. $\mathrm{El}$ arte aborigen reflejó la intensa y compleja vida social de sus pueblos, revelando su entrañable vinculación con la naturaleza. Huacos y tejidos representan verdaderos mensajes de una cultura, con valores estéticos y humanos que no ha repetido el hombre costeño de la Colonia y la República. Buena guía para conocer algo de la poderosa vibración humana, "del vitalismo que acompaña de principio a fin la voluntad expresiva" del arte mochica, es el libro de A. Jiménez Borja (Moche).

Pero estas típicas poblaciones costeñas son de hecho fuentes de inspiración literaria. Tienen escenario propio, tipos humanos definidos, modalidades económicas peculiares. De ellas salieron autores de esperanza como el poeta Berríos y el relatista Nicho, a más de Alejandro Manco Campos, autor de Valle algodonero. La madre de José Carlos Mariátegui, el célebre inválido y gran amauta, fue de Huacho y tuvo el perfil aguileño inconfundible del yunga. José Olaya, acaso el personaje más ejemplar del heroísmo peruano en la lucha por la Independencia, procedía de una comunidad pescadora de Chorrillos. En un ensayo anterior (La naturaleza y su expresión literaria), registré a los primeros reveladores de la cholada costeña: Valdelomar, Fernando Romero (Cuentos de mar y playa), José Félix de la Puente (Las islas azules), los relatistas de Chancay, provincia nuestra, ${ }^{5}$ José Eulogio Garrido (Estampas de Moche) y la contribución literaria de José Mejía Baca (Aspectos criollos), al lado del estudio sociológico de Hildebrando Castro Pozo (Nuestra comunidad indigena).

No es menos definida la personalidad del injerto en el mapa costeño. Aunque a veces se le excluya en los cuadros raciales, su figura está presente en la vida cotidiana de los pueblos. Tambero, peón, comerciante, cocinero, soldado, profesional, el injerto se mezcla y actúa en la vida nacional. La pintura tiene notables exponentes, el teatro lo ha caracterizado y hay nombres como los de Zulen y Fonken, inscritos con orgullo en nuestra vida intelectual y en la historia de las luchas obreras. Correspondería a José Ferrando su introducción en la novela (Panorama hacia el alba). César Vallejo había captado la psicología del chino - no propiamente del injerto- en sus conocidos menesteres de los fumaderos de opio y las casas de juego (Cera, Escalas melografiadas). 
El escenario abrupto de la sierra es el verdadero asiento de cholos e indios. Pocos blancos figuran en los medios urbanos, campamentos mineros, latifundios, comandando el gobierno, las industrias de extracción, la institución feudal del gamonalismo. La sierra alberga el $73 \%$ de la población peruana, pero tan sólo el $36 \%$ de la que vive en ciudades. Un mapa racial de la población serrana, tomando como índice el porcentaje de sangre indígena, daría por aproximación 50, 70 y $80 \%$ para Norte, Centro y Sur. Esta última región es predominantemente indígena; el mestizaje muestra claramente sus flujos en el Centro; el Norte es una región chola mayoritaria. Las correspondencias lingüísticas del mestizaje indican que Aymara y Quechua son más puros en el Sur, predominan en el campo y son preferidos al Castellano en las ciudades, para todas las efusiones de la vida intima; el Centro equilibra el uso de Quechua y Castellano, pero el idioma nativo ha ido adquiriendo diferencias de zona a zona y aun de provincia a provincia (quechuas de Ayacucho y Junín; Huanta y Jauja); aunque amagado de quechuismos, voces tallanes, mochicas y chimús, el Castellano prepondera en el Norte, sobre las pequeñas islas quechuas - reductos supervivientes de los principales ayllus incaicos de la región- en las campiñas de Conchucos, Contumazá, Huamachuco, Cajamarca, Chota, Huancabamba.

Las variantes de raza y lengua tienen sus equivalentes en indumentaria, costumbres y folklore. La bella acuarela de ponchos, llicllas, anacos y chullos de Centro y Sur desaparece o atenúa sus colores en la región norteña, donde los ponchos lucen la simple gama de los tintes nogal; los colores netos pero individuales de pollerones y faldellines; el amarillo vegetal de los sombreros de junco y palma. No faltará por completo el guiño colorista -alforjas bicolores, fajas de trama polícroma, faldas y rebozos talqueados-, pero dominan colores y texturas de driles, manfores, percales, etaminas, cretonas y pañuelos floreados, de importación. Pinkullos y pututos no resuenan familiarmente en los Andes norteños. Más que la penetrante melancolía de las quenas, riega su liviana tristeza el borbotón melódico de las antaras. Marinera y serranita son los bailes regionales del Norte, mientras cashuas, huaynos y cachasparis dominan en Centro y Sur. El yaravi arequipeño o la muliza cerreña, corresponden al triste de Cajamarca, la Libertad y la sierra de Piura. 
Arpas y guitarras son usuales en el Norte, como en campiñas y pueblos de Cuzco, Ayacucho y Arequipa. El instrumento común -como si fué el comunitario expresador del sentimiento musical y coreográfico de los Andes- es la caja o tinya, el viejo tambor incaico que presidió el compás de los taquis fastuosos y los haylles triunfales del Imperio. ${ }^{\circ}$

Estas lógicas diferencias que ha marcado el ritmo lento o apresurado del mestizaje, no alcanzan a borrar en la población serrana las identidades profundas que le nacen de la comunidad geográfica, la ubicación social, la historia común. El serrano no ha perdido el sentimiento de la naturaleza; sigue atado a los Andes "por el cordón umbilical de su propia alma". Nuestra sierra es fundamentalmente agraria, rural. En las comunidades indígenas y mestizas supervive la parafernalia ritual del indio, en torno a cultivos y ganados. Es la subsistencia o el renuevo secular de la religión panteísta y trascendente a la Mama-pacha, la madre Tierra. El vínculo a ella se vuelve más entrañable con "la actitud y la manera de trabajarla", esto es, con el congénito agrarismo indígena. El hombre sigue siendo el trabajador orgánico que no entiende la vida sino trabajando, como el productor de Tahuantisuyo, del alba a la noche, con pasión y esmero, codo a codo al hermano, al vecino, al prójimo de la comunidad. $\mathrm{Y}$ tal como en los Ayllus imperiales, el trabajo comunal mantiene las tónicas cualidades estimulantes de entusiasmo, alegría, culto ritual, emoción religiosa, solidaridad.

Pero estas virtudes no saldrán a luz cuando la tierra es ajena y el trabajo forzado. Ellas presiden el trabajo de los comuneros, pero la sierra no está ocupada únicamente por comunidades. La mayor porción de tierra cultivable es propiedad de latifundios, una variante de la encomienda costeña, $y$, ambas, típicos productos del mismo régimen económico feudal subsistente en la República. Como el régimen de trabajo no escapa a las determinaciones del régimen de propiedad, propiamente en la agricultura, la población enyugada al servicio de los gamonales soporta una trágica servidumbre. Por lo que una parte de indios y cholos vive en comunidades; algunos en pequeños poblados o en campiñas con pequeñas parcelas; una tercera parte del total corresponde a los que son colonos, pastores, yanacones o aparceros en las haciendas serranas. Aunque la explotación feudal tiene diferencias de grado, es común el bárbaro régimen de 
opresión y esquilmamiento. El gamonalismo es toda una institución que no ampara la ley, pero sí la odiosa tercería prepotente de autoridades y gobiernos. Representa la actitud mental de un Estado regido por la feudalidad intacta de los grupos privilegiados.

Contra esta institución serrana del feudalismo, la comunidad ha librado dramáticas batallas. El duelo no termina aún. En gran parte de las tierras comunales cayeron en manos del gamonal vecino, o los comuneros se han uncido, impotentes y acorralados, a la esclavitud del pongaje, el tributo de los brazos, el préstamo usurario del agua. Ha supervivido, pese a todo, bien que desgarrada y en zozobra constante, la vieja institución imperial. Tanto como el mantenimiento de parte de sus tierras propias, nos importa comprobar que perpetúa las fecundas tradiciones del esfuerzo cooperativo, el folklore secular, sus códigos morales, el régimen colectivista de la propiedad y el colectivo usufructo del trabajo y la producción.

El indio más o menos libre, vigoroso, altivo, productor, es el comunero. El colono de los latifundios casi es un ex-hombre, derrotado, impotente, aplastado bajo el yugo del amo, perseguido por las turbias acechanzas del fraile, el gobernador, los tinterillos y toda la jerarquía de explotadores puesta al servicio del gamonalismo rapaz y opresor. Las insurrecciones serranas han salido de las comunidades indias o mestizas: José Gabriel Condorcanquí y su gran rebelión social, ${ }^{7}$ el gallardo levantamiento del amauta Atusparia y Ushcu Pedro ${ }^{8}$ y los cientos de sublevaciones ahogadas en sangre, y sin historia, que han conmovido la sierra peruana. E1 indigena humillado por el abuso, con la degradación del yugo, degenerado por el vicio es el que observan generalmente los turistas o exportan algunos relatos peruanos incomprensivos o interesados. El otro "indio", orgulloso y sobrio, potente y desder̃oso, conserva lo mejor de la tradición nativa y tiene en la sangre los acentos viriles, la tónica masculina, el elemento dominante para trasmitir la energía creadora de la raza. En ese hecho se funda el orgullo del cholo por sus cabeceras indias. Ahí arraiga, también, la convicción de que la suerte del Perú no podrá definirse "sin el indio o contra el indio". ${ }^{2}$

Sol, están devorando a tus hijos, La tierra es el hombre, Los campesinos y otros condenados (Serafín Delmar) son relatos que revelan aquella doble realidad del indio comunero y colono. Debemós recurrir a José María Arguedas (Agua), para entender el mun- 
do peculiar, trágico, indisculpable de un sector quechua del Sur. Clorinda Matto de Turner (Aves sin nido) puso al indio como problema en el tapete de las letras, descubriendo las cartas sucias del juego republicano. No hay exhibición más cruda de sus verdugos, particularmente del aquel espécimen, renuevo de los Valverdes y Arriagas del pasado. Como documento para comprender esta realidad opresora del fraile y fundamentar la posición anticlerical inobjetable de las conciencias honradas, recordemos el acusatorio libro de Narciso Aréstegui (El Padre Horán. Escenas de la vida del Cuzco), para no salir del campo puramente literario y llegar a las fuentes primordiales de Vigil, Rosell y González Prada.

Antes que Clorinda Matto y Narciso Aréstegui, Humboldt había visto al indio en su categoría de problema y lo inscribió en sus relatos, enseñándonos a mirar la tierra en su dimensión estática de belleza geográfica, al propio tiempo que en su dimensión dinámica, como escenario del hombre que la vive con su tragedia a cuestas. Los ensayistas - Sulén, González Prada, Mariátegui, Haya de la Torre, Basadre, L. A. Sánchez, Castro Pozo, Abelardo Solís, C. A. Espinoza Bravo, Ugarte, Valcárcel, Encinas, Uriel García, M. Arriola, Velazco Aragón- ven mejor el tremendo rango del problema del indio, manoseado desde la ingenuidad hasta la impudicia, como elemento decorativo, motivo patriótico, señuelo turístico, en politica y literatura.

Sara-cosecho (M. Robles Beltrán) es un documento reciente para conocer el status de indios y cholos en la zona de Apurimac y advertir los interesantes flujos del mestizaje. Pero la entraña psicológica de indios de arriba y abajo, de la quebrada o la jalca, comuneros o colonos, no tiene traducción literaria mejor lograda que la de Enrique López Albújar (Cuentos andinos, Nuevos cuentos andinos).

En la sierra no hay una realidad uniforme. Junto a la realidad indigena está la de los cholos y se puede hablar de una realidad intermedia que corresponde a los trances culminantes del mestizaje. Dijimos que la región norteña es predominantemente chola y que el acholamiento sigue una línea de avance lento pero seguro, de Sur a Norte. Iguales condiciones geográficas condicionan la vida de cholos e indios, y el serrano tiene un acento común de expresión frente a la costa, origen y fundamento del dualismo geográfico 
y espiritual, bien estudiados por Mariátegui y el mexicano Sáenz (7 ensayos de interpretación de la realidad peruana, Sobre el indio peruano, respectivamente). Agreguemos que, junto al cruce procreador de tipos humanos contrastados, factores de diversa índole siguen operando en la sierra para determinar nuevas modalidades de vida. Carreteras y ferrocarriles soldaron contactos entre pueblos y regiones, movilizando el comercio y estimulando las industrias locales. La explotación minera en gran escala abrió la perspectiva del trabajo "libre" y mejor remunerado. El enganche ${ }^{10}$ de braceros a las haciendas de la costa - huérfana del brazo esclavo de negros y coolíes- provocó emigraciones temporales o definitivas.

La sierra no albergaría ya sólo sus tipos clásicos: comuneros, colonos, arrieros, pastores, artesanos. Surgieron el trabajador de las minas y el enganchado; al lado de campesinos y pastores aparecen mecánicos indios, choferes mestizos, trabajadores aventureros. El salario alto, la nueva indumentaria, los flamantes hábitos, la asimilación de los injertos técnicos y culturales representan conquistas indudables, pero impotentes para desarraigarles el tenaz sentimiento por la tierra, sus realidades y tradiciones.

José Ferrando cruzando el Perú de costa a selva, pasa por las tierras mineras de Junín (Panorama hacia el alba). Contemplando a indios y cholos les grita esta frase dura y esperanzada: "Indio cobarde: levántate y pelea; párale al blanco; forja tu destino"; "Cholo animal: despierta, que eres nuestra esperanza". La doble expresión comprueba la existencia de los dos tipos representativos de la sierra y su significación social presente y futura. Tales frases, lanzadas en el nuevo escenario económico, llevan agazapada la denuncia de una realidad que, si bien emancipa al hombre de la brutal tutela gamonalista, to unce a la nueva servidumbre del overall, el salario "libre" y el time-check.

César A. Vallejo (Tungsteno) muestra con un "realismo sin literatura" el drama de las minas que comanda el gringo con su camarilla mestiza y obsecuente de capataces, confidentes, jueces y subpréfectos. Revelar al enganchado fué el intento, no definitivo, de J. Ortiz Reyes (Simache). El logro más honrado y constructivo en la presentación literaria del' mestizo serrano del Norte fue obra de Abelardo Gamarra (La vida en Pelagatos, Cien años de vida perdularia). Para estudiar la psicología real del mestizo en la vida 
urbana, tanto como su conducta moldeada por las imposiciones corrompidas y corruptoras de la política criolla, el centralismo, la Iglesia, no hay documentos más sinceros e inobjetables que los del gran huamachuquino, olvidado con injusticia por la crítica oficial u of icializada, y evitado en los "panoramas" de la literatura peruana que fraguan pupilos y lacayos de unas castas vapuleadas inolvidablemente por el inolvidable Tunante.

Ciro Alegría tiene una exposición más amplia de tipos serranos en La serpiente de oro, Los perros hambrientos y El mundo es ancho y ajeno. Su obra representa, también, un extraordinario esfuerzo para exhibir la vida anímica, la tradición, el folklore, las modalidades económicas y la ubicación social de los cholos, desde la banda fluvial de los temples hasta las jalcas pastoras. Cholos son igualmente los personajes de El Donato (Guillermo Mercado), Cholerias (Porfirio Meneses), Escalas melografiadas (César Vallejo), Tierras del alba (F. Izquierdo Ríos), Tierra mía (A. Pelaes Bazán), La Guacha (J. Garrido Malaver) los relatos de Crónicas de andar y ver, Carbunclos (J. Eulogio Garrido), Diez acuarelas y un pueblo, Cuentos cholos. (A. Arias Larreta), y los tipos que accionan en cuentos no reunidos en volumen, pero que revelan la fuerza creadora y el porvenir literario de sus autores: A. Contreras Sosa, Rubén Barrenechea, Jorge Moscol, Mario Negro, Arturo Briceño Zapata, Teófilo Espejo Núñez, Maurilio Arriola Grande, Rómulo León, Juan Camino Varela.

No está agotada ni mucho menos la múltiple temática de la sierra peruana. Desde el paisaje hasta el pueblo, pasando por el hombre y su problemática humana y social, hay una riquísima cantera esperando el voluntarioso equipo de relatistas que la saque cabalmente en hombros a la literatura nacional. Por supuesto que no sirven hombros turistas o deshumanizados, para esta tarea. Respetando las calidade's puramente estéticas de toda obra literaria, novela o cuento se despersonalizan si no hunden la garra sincera en las realidades de su ámbito, para traducir del paisaje, el sentimiento, la emoción del hombre, las vicisitudes de la comunidad. Desde este punto de vista, relato serrano sin antenas para captar las resonancias de la lucha anticaciquil, no es versión fidedigna; relato que elude el registro de los impactos imperialistas en la economía y la libertad de los pueblos mineros, es engendro antiperuano; relato 
fugado de la tierra o del hombre o de la comunidad, es, en fin de cuentas, masturbación intrascendente en la legítima tentativa de estructurar una literatura peruana.

Igual en la poesía. Algunos poetas provincianos envalentonados por la gloriola de un galardón de aldea, discutible y aldeano, hablan con candorosa insistencia de su inefable "mensaje de belleza", tal si la poesia fuera una suerte de "exudación estética" autónoma y desarraigada del mundo, la vida, la historia. Por una vieja y elemental verdad sabemos que el poeta no nace por generación espontánea y que sus creaciones no son fenómenos ultraterrenos, de origen etéreo o mero sentido mágico. Esta no es ocasión de ahondar el tema. Me remito al capítulo respectivo de mi libro Radiografia de la literatura peruana ("El purismo o la evasión"). Y a mi próximo ensayo El onanismo lírico en la literatura. Baste decir, por hoy, que en el supuesto de que exista obra de arte en plenitud axiológica, aun con tema fuera del motivo económico, social o simplemente humano, si tal obra adquiere valor estético, por el estilo y la forma interior en que sus emociones se alumbran, combinan y expresan, en cambio la tónica emotiva de la obra y las directivas formales de la cristalización han de corresponder a la sensibilidad típica del medio y de la época. Martínez Bello les aconsejaría: "aunque el poema no cante la lucha revolucionaria ni la trinchera, ha de poseer el ritmo de vida, el sentimiento de la naturaleza, la concepción del mundo, el sentido emocional del estado de ánimo que vive la humanidad". No les digamos que hay función social del Arte - esto hace levantar en protesta las manos cloróticas de los deshumanizados- pero sí, y sin remedio, función social del artista. Porque una cosa es que el Arte no tenga fin utilitario inmediato y otra cosa que carezca de sentido. Ese sentido, tal rumbo, su tendencia trascendente, afloran inexorablemente en el mensaje de poetas, pintores, novelistas, músicos que no planifican la belleza, no deliberan el sentido tendencioso de sus obras, pero cuyo espíritu creador responde, bien o mal, a los estímulos sociales de su conciencia individual, de la sensibilidad colectiva, de la tradición y del momento histórico que viven. El arte, además, es un lenguaje, un vínculo de relación humana, de comunicación social. Quien crea una obra de arte tiene algo que decir al mundo y a la sociedad en que vive. Ese mensaje, ya lo han dicho antes de mi, no puede darse 
en lenguaje paranoico o equilibrado en el maromeo verbal de una poesía sin clave para la emoción del hombre y sin acústica para los ecos sociales de su espacio y su tiempo.

Nadie negará el rumbo definido y la trascendencia social de amautas y haravicus, ${ }^{11}$ como leales intérpretes de la sensibilidad colectiva del Tahuantisuyo. La copla mestiza colonial - con altos, bajos o medianos quilates literarios- es una neta expresión de la combativa actitud psicológica de las clases populares. Garcilaso de la Vega y Mariano Melgar procrean, en dos ortos históricos, la efusión lírica inicial del cruce de sensibilidades. ¿Quién discute la evasión de los románticos peruanos, como la resultante de una conciencia individual desconcertada dentro de un subconsciente colectivo, enturbiado ya por el desencanto republicano, en un período anárquico que mangonean los caudillos y capitalizan las castas coloniales supervivientes? González Prada es la primera afirmación de la conciencia nacional, y el mensaje de su poesía ataca las fortalezas académicas y españolizantes, pero abre su sensibilidad a las resonancias del mundo más allá de Lima y sus muros, más lejos de la costa y sus castas, por encima de los clanes literarios y del avemaría feudal.

El que los colónidas no hayan definido sus tendencias, no quita nada a la emoción nacional que se insinúa en los primeros y que despunta mejor en su segundo grupo "emancipado del Girón de la Unión y su Palais Concert". El contenido de su "descontento literario" es claro signo del malestar social del Perú, como lo fué, en forma más concreta, la Insurgencia literaria provinciana representada por los Grupos de Norte y Sur, (Trujillo, Arequipa y el Grupo Kollavino de Puno).

Pero serían los sucesos políticos, económicos y sociales de este siglo, a partir del año 26 , los que empezaran a bocetar mejor los perfiles de la conciencia peruana. Derivación o integración lógica de este fenómeno son los recados poéticos que intentan expresar la nueva sensibilidad. Contrastados, dispares, a veces contradictorios, ya pueden exhibir orgullosamente el común denominador de peruanos. El mensaje nacional de nuestra sensibilidad, andando el tiempo, no ha de ser sino la conjugación por venir de estas tónicas regionales. 
Desde Alejandro Peralta -o mejor desde el Grupo Kollavino integrado por Peralta, Gamaliel Churata, Luis de Rodrigo, Landaeta, Navas- comenzó en el Sur la revaloración poética del indio. González Prada es el antecedente precursor con Mariano Melgar, como lo es Clorinda Matto en la novela para toda Indoamérica. Peralta descarna al indio de la estepa y se da con su angustia metafísica, su agobio social y la expresión poética que traduce vigorosamente en El Ande y Kollao. Luis de Rodrigo moviliza esa sensibilidad a lo ancho del paisaje kolla, haciéndola parlar en todos los tambos del trabajo, el amor, la injusticia. Eustasio Arewanka descubre su impulso social cantando en quechua al amauta J. C. Mariátegui. Al grupo de reveladores de hombre y paisaje del Titicaca pertenecen Emilio Vásquez, Mario Chávez, Dante Navas, Alberto Cuentas y aquella voz desgarrada y agresiva, de arrullo melodioso pero de garra ruda y sensual, de Emilio Armaza (Falo).

Guillermo Mercado, Luis Nieto, Angel Aragón representan al cholo dinámico, rijoso, optimista del valle serrano del Sur. La estampa lírica del mestizo se cuartea aquí y allá por el aguacero tenaz del abuso, la miseria, los rencores, pero el "nuevo indio" forcejea con su drama, y su grito de rebeldía, de alborozo o de amor, parece encresparse como un arcoiris que sostiene al horizonte sobre los lomos voluntariosos. Este no es el cholo que pinta el verso de José Varallanos o Fabio Xammar. Más identidades tiene aquel cholo con el voluntario enrolado en las tropas de la emoción social (Magda Portal-Serafín Delmar) y con el mestizo antirretórico y de vitalidad agresiva que reveló el Samaniego de Cántaro, no el Samaniego deshumanizado inconcebiblemente en el trapecio verbal de El canto inefable.

César A. Vallejo expresa parcialmente el trágico desbarajuste de emociones mestizas (Los heraldos negros). Ese mismo mestizo santiaguino tiene la traducción honda y cristalina de Felipe Arias Larreta (Antara). La emoción mestiza alcanza el dramatismo épicolírico en el ancho registro de Julio Garrido Malaver. No puedo ser juez y parte, por lo que me inhibo de comentar mi contribución a la poesía chola, desde el libro inicial La baraja del Cholo hasta Pregones, pasando por Voces que recogió mi meridiano y El hondero de la laja encendida, así como mis trabajos por la reivindicación 
literaria del cholo (Realidad lírica peruana, Tónica regional del cholo, Radiografia de la literatura peruana).

He dejado para el final a Mario Florián, Anaximandro Vega y Nestor Gastañaduí. Pertenecen a tres pueblos norteños de acentuada influencia indígena: Contumazá, Chota, Huamachuco. Son las islas quechuas a que me he referido ya. Anaximandro Vega antecede cronológicamente a los demás, pues actuó en el magnífico equipo de la revista Sierra, 1927. Gastañaduí tiene tono menor y emoción suave, pero su verso capta el brioso discurrir de unos mestizos que sienten algo más que las emociones del amor y la siembra, la embriaguez de la chicha y la cocaína secular, de los ritos católicos. En uno y otro, las expresivas señales de los vocablos quechuas cruzan iluminando la trama del castellano. La personalidad lírica de Vega, superior a muchos "puristas" que propagandea la crítica tartufa y tribal, la rescaté en parte, justicieramente, para inscribirla en los anales de nuestra literatura (Realidad lirica peruana, Washington).

Mario Florián obtuvo el Premio Nacional de Poesía el año 1945, con Urpillay, versión poética siglo $\mathrm{xx}$ de los eternos haravicus, cuya trascendencia estética no ha sido estudiada en nuestra nueva poesía. Es la única vez hasta hoy, que ese Premio Nacional se concede con justicia. Por sus valores estéticos y humanos cualquier Pastorala de Urpillay cstá sobre todos los Sonetos de la rosa de Martín Adán; por su jerarquia estética y su aliento social, un poema de la Pequeña antología de Florlán vale por diez variaciones deshumanizadas de la misma melopea purista de Gustavo Valcárcel, en Confín del tiempo y de la rosa.

Florián manipula las calidades líricas de Vega, la contenida emoción de Gastañaduí, el juego natural y sugestivo del castellano quechuizado en ambos; pero introduce una línea melódica igual o superior a la del César Vallejo de los Heraldos negros y un alegato reivindicador que no pulsó en tal libro tal poeta. Esa tónica poética popular, multitudinaria, humanísima, lo aleja de la retórica pedestre o del purismo escapista y le da capacidad para poner su propio hito significativo en el camino de la literatura peruána - no del Perú- jalonada por el tránsito de Garcilaso, los copleros, Melgar, Clorinda Matto, Abelardo Gamarra, González Prada. 
José Carlos Mariátegui hablaba de la ninguna significación sociológica y económica de la selva, convertida en una especie de dominio colonial del Estado peruano. Tal status va modificándose lentamente, merced a los intentos civilizadores y de explotación industrial; pero no se ha transformado al punto de poder contradecir la afirmación de los Siete ensayos de interpretación de la realidad peruana. La selva sigue siendo un mundo salvaje e inaccesible en su mayor extensión, con unas cuantas poblaciones erigidas a lo largo de sus ríos, como un Perú aparte que gravita al Este por su geografía y su comercio, al estilo de todas las aguas de la gran hoya amazónica.

Aparte de los núcleos mestizos y los grupos de blancos inmigrantes, la población de la selva se compone de tribus semicivilizadas y salvajes. Usan arcos y flechas o manejan cerbatanas y lanzas; se cubren con la típica cushma o viven desnudos; siguen en vida nómade o han iniciado la etapa agrícola. Hablan multitud de dialectos, desde el primitivo inje-inje hasta el más evolucionado aguaruna-campa. Los estudiosos de la geografía humana distinguen a los aguarunas agricultores; los huitotos (algunos antropófagos, según Wiesse); los combis del Alto Ucayali (en contacto con blancos y mestizos); los campas del Urubamba; los cashivos, que emplean aún herramientas de piedra, y los sirineires en la región de Madre de Dios. Con blancos y mestizos forman una población calculada en 280,000 habitantes.

El capítulo de la selva es cl más reducido en la literatura peruana Auundan las dcscripciones geográficas y los relatos de exploradores, desde Orellana y Pizarro hasta Raymondi y Mesones Muro. Poetas foráneos y no nativos - con excepción del esfuerzo de Hernán Medina Pinon (Esquifes de la tarde) - han cantado a la selva. No hay un libro cabal de poemas con la versión épica y lírica de la floresta amazónica. Chocano tiene cuadros impresionantes (El derrumbe) y cuaja su poesía con la novedosa nomenclatura de fauna y flora. Julio Garrido ha producido el poema más vigoroso posiblemente, en su Tríptico de costa, sierra y selva.

A novela $y$ cuento pertenecen las primeras avanzadas en la interpretación humana y paisajista de la selva. Manuel Beingolea y J. C. Chirif sacaron los primeros cuadrośs en sus cuentos. Fernando Romero daría luego muestras más completas de ese mundo verde 
y fluvial en 12 novelas de la selva. Francisco Izquierdo Ríos y Alfonso Peláez Bazán han captado la vida de cholos y montuvios, en las cabeceras de la selva. La novelación de Ciro Alegría es otra cosa; conjuga los elementos de vida, paisaje y drama, con las dos bandas del Marañón, en un bello concierto del flujo y reflujo de acciones entre la naturaleza y la comunidad. Arturo Burga Freytas (Ayahuasca) y A. Hernández (Sangarima), sin olvidar el escenario, se empeñan en descifrar el dialecto mágico de mitos, tabús y leyendas, cuya clave se enraiza al subconciente colectivo respondiendo a la requisitoria inmemorial de los influjos cósmicos. José Ferrando (último capítulo de Panorama hacia el alba) lleva sus personajes al corazón de la selva, para rematar el drama vigoroso que comenzó en el Callao. En ese capítulo traza la estampa literaria del hazañoso cauchero Fitzcarrald. Este mismo formidable personaje ha sido tratado en una biografia completa, por Ernesto Reyna (Fitzcarrald, el rey del caucho).

Tras este suscinto panorama podemos expresar que los cholos costeños, zambos, mulatos e injertos de la costa son más personajes que autores literarios; cholos de la sierra - con mayor o menor sangre india - son a la vez actores y autores; ningún creador montuvio tiene la selva. En un balance general, el cholo tiene un mayor porcentaje, entre autores de todos los géneros - novela, poesía, cuento- y los personajes de la sierra han sido incorporados más intensa y mayoritariamente en la literatura peruana. No hay un indio de pura sangre en la República - la arqueología tiene al insigne Tello, la literatura colonial al famoso Lunarejo; Eustasio Arewanka fué una promesa- ni la selva engendra sus propios autores. Ello nos recuerda los dos vastos problemas que ha de resolver el Perú, para integrar su economía, conciencia y cultura: el problema del indio y el problema de la selva. Capitalizar al indio y capitalizar la selva representan dos deberes de vieja y desoída justicia. Hasta ahora son problemas que tienen irremediablemente baldado el porvenir del Perú. 


\section{NOTA S}

1 Intención de este trabajo es registrar autores y personajes peruanos tratando al hombre en cuanto a su aptitud para crear $y$ expresarse originalmente en la literatura, y en cuanto a su actitud humana y social, como actor en la poesía, la novela y el cuento. La necesaria división en tipos y sub-tipos raciales obedece a ese propósito, no a prejuicio racista alguno, aunque es inevitable la deducción del antagonismo social y literario que se entabla entre las clases media, campesina, proletaria y los grupos dominantes, dentro de un régimen económico injusto $\mathrm{y}$ anacrónico. Por otro lado, se trata de la literatura peruana - no del Perú-, por lo que no se incluyen obras de prosa o verso ni escritores y poetas de mayor o menor valor literario, pero de categoría indefinida para los fines de este ensayo; obras que pueden merecer un trabajo aparte $y$ que podrian agruparse en un núcleo singular sin partida de nacimiento en el Registro Civil Peruano de la inquietud, la emoción, el estilo y la expresión.

2 Mitimaes: poblaciones rebeldes trasladadas a regiones lejanas o súbditos leales llevados a las zonas levantiscas del Imperio de los Incas.

3 Notas poéticas del enganchado: Anaximandro Vega: poema Qquera, publicado en Sierta. A. Árias Larreta: Poema V (La baraja del cholo); Tránsito y pasión del enganchado ( $E l$ hondero de la laja encendida).

4 Caballito de totora: embarcaciones de paja de totora, parecidas a los caballitos de mar, usadas por los pescadores de la Costa y del lago Titicaca.

5 Chancay, provincia nuestra. (Ver Bibliografía.)

6 Taqui: baile colectivo. Haylle: canción alegre del trabajo y la victoria (Imperio de los Incas).

7 Libros de Francisco Loayza (Tupac Amaru) y de Valcárcel Carlos (Tupac Amaru, Edit. Fondo de Cultura Económica, México, 1945).

8 El amauta Atusparia (Ernesto Reyna, Edit. Minerva, Lima, 1930).

9 Téngase en cuenta que uso el término de indio, con las limitaciones apuntadas en "Realidad lírica peruana" (Revista Iberoameticana, noviembre de 1941) y en "Radiografía de la literatura peruana".

10 Enganche: contrata de peones serranos, para los valles de la costa.

11 Amautas y haravicus: creadores de la literatura épica y lírica, en el Tahuantisuyo. 


\section{B I B L I O G R A F I A}

C O S T A

Castro Pozo, Hildebrando, Nuestra Comunidad Indigena, Lima, Edit. E1 Lucero, 1924.

Camino Calderón, C., El dạño, Lima, 1940.

Dfez Canseco, José, Estampas mulatas, Lima, 1937.

FERrando, José, Panorama hacia el alba, Lima, Imp. El Universal, 1940.

Fonseca, Guillermo, H. COlAn SECAs, I. Nicho, López GutrérRez, Chancay provincia nuestra, Huacho, Edit. Nicho, 1943.

FUENTE, Nicanor de la, La feria de los tomances, Lima, 1938.

Falcón, César, Pueblo sin Dios.

JIMÉNEZ BORJA, Artụto, Moche, Lima, 1938.

LÓPEZ AlBÚJar, Enrique, Matalaché, Lima, 1928.

-. Poemas afro-yungas, Lima, 1937.

Mac LeAn, Roberto, Negros en el Perú, Lima, Edit. Miranda, 1947.

- Negros en el Nuevo Mundo, Lima, Edit. P. T. C. M., 1948.

MANCo CAMPos, Alejandro, Valle algodonero, Lima, Edit. Bustamante, 1942.

MEJfA BACA, José, Aspectos criollos, Lima, Imp. Lux, 1937.

MACEDO, María Rosa, Rastrojo, Lima, Edit. G. Lenta, 1944.

ORTIZ REYES, José, Simache, Lima, Edit. Barrantes, 1941.

PAREdes, Rómulo y León BARANdiarán, A golpe de arpa, Lima, 1935.

PUENTE, José Félix de la, Las islas azules, Lima, 1944.

ROMERO, Fernando, Cuentos de mat y playa, Lima, Edit. C. I. P., 1940.

TORRES DE VIDAURRE, José, Romanceto criollo, Lima, 1936.

VAldelomar, Abraham, El caballero Carmelo, Lima, Imp. de la Penitenciaría, 1918.

VAllejo, César A., Escalas melografiadas, Lima, Edit. Hora del Hombre, 1948. VELÁSQUEZ, Juan Luis, El perfil de frente, Lima, 1927. 
S I E R R A (PROSA)

Alegría, Ciro, La serpiente de oro, Santiago de Chile, Edit. Nascimento, 1936.

- Los perros hambrientos, Santiago de Chile, Edit. Zig-Zag, 1939.

- El mundo es ancho y ajeno, Santiago de Chile, Edit. Nascimento, 1940 .

Arguedas, José María, Agua, Lima, Edit. C. I. P., 1927.

Aréstegur, Narciso, El Padre Horán, Cuzco, 1848.

ArIas LARreta, Abraham, Cuentos cholos, Edit. Avance, Huaraz, 1932.

- 10 acuatelas y un pueblo, Lima, Edit. Lux, 1935.

BELTRAN Robles, José, Sara-cosecho, Cuzco, Edit. Rozas, 1940.

Delmar, Serafín, Sol, están devorando a tus hijos, Buenos Aires, Edit. Americalee, 1941 .

- La tierra es el hombre, Buenos Aires, Edit. Americalee, 1942.

- Los campesinos y otros condenados, Santiago de Chile, Edit. Orbe. 1945.

Garrido Malaver, Julio, La Guacha, Lima, Edit. Guía Lazcano, 1944.

Garrido, José Eulogio, Carbunclo. Trujillo, Edit. La Industria, 1947.

Gamarra, Abelardo, Cien años de vida perdularia, Lima, Tip. Abancay, 1921.

Dulanto Pinillos, Jorge, Estampas andinas, Lima, C. I. P., 1939.

EspinozA Braco, C. A., Facetas de Jauja, Jauja, 1937.

IZQUIERDo Rfos, Francisco, Tierras del alba, Lima, Edic. del Ministerio de Educ. Pública, 1944.

- Ande y selva, Lima, Edit. Libro Peruano, 1939.

LÓPEZ AlBÚJAR, Enrique, Cuentos andinos, Lima, 1920.

- Nuevos cuentos andinos, Santiago de Chile, Edit. Ercilla, 1939.

MerCado, Guillermo, El Donato, Arequipa, 1935.

Meneses, Porfirio, Cholerias, Lima, Edit. del Ministerio de Educación Pública, 1944.

PelÁz BAzÁ, Alfonso, Tierta mia, Lima, Edit. del Ministerio de Educación Pública, 1944.

TURner, Clorinda Matto de, Aves sin nido, Lima, 1899.

VAllejo, César Abraham, El Tungsteno, Lima, Edit. Hora del Hombre, 1948. —. Fabla salvaje, Lima, Edit. Hora del Hombre, 1948. 
POESI $\mathrm{A}$

Arguedas, José Maria, Cantos keswas, Lima, Edit. Libro Peruano, 1936.

ARMazA, Emilio, Falo, Puno, 1926.

Arias Larreta, Felipe, Romanceto de Crusgay, Trujillo, Edit. Burgos, 1942.

-. Antara, Lima, Edit. Sayari, 1948.

Arias LARreta, Abraham, La baraja del cholo, Buenos Aires, Edit. Indoamérica, 1945.

—. Las voces que recogió mi metidiano, Lima, Edit. América, 1937.

- El hondero de la laja encendida, Lima, Edit. Cavero Mariátegui, 1939.

-. Pregones cholos, Trujillo, Edic. clandestina, 1944.

—. Pequeña antología, Trujillo, Edit. Sayari, 1947.

Chávez, Mario, Cocca, Puno, 1926.

Florián, Mario, Urpillay, Lima, Edit. Ministerio de Educ. Pública, 1945.

Pequeña antología, Trujillo, 1947.

Garrido Malaver, Julio, Canto a la primavera en varios momentos, Lima, Imp. Guía Lazcano, 1940.

- Sierra, costa y selva, Lima, 1943.

GuIlléN, Alberto, Cancionero, Arequipa, Edit. Portugal, 1934.

Peralta, Alejandro, Ande, Puno, Edit. Titicaca, 1926.

-. Kollao, Lima, 1934.

PORTAL, Magda, Costa Sur, Lima, 1942.

MERCADo, Guillermo, Un chullo de poemas, Arequipa, 1936.

- Tremas, Lima, Edit. Antena, 1930.

NIETo, Luis, Charango, Lima, Edic. del Ministerio de Educ. Pública, 1945.

Rodrigo, Luis, Puna, Lima, Edic. del Ministerio de Educ. Pública, 1945.

Samaniego, Antenor, Cántato, Lima, Edit. Miranda, 1944.

Vallejo, César Abraham, Los heraldos negros, Edit. de la Penitenciaría, 1918.

VAlle GoYcocheA, Luis, El sábado y la casa, Lima, C. I. P., 1935.

VÁsQUEZ, Emilio, Altipampa, Puno, 1933.

-. Tawantisuyu, Arequipa, 1934.

- Kollasuyu, Lima, Edit. Antena, 1940.

VARALlanos, José, Romancero cholo, Lima, 1936.

XAMMAR, Fabio, Wayno, Lima, 1937.

Xandoval, Francisco, Maya, Trujillo, 1944. 
SELVA

BURGa FreYTAS, Arturo, Ayahuasca, Lima, 1936.

Ferrando, José, Panorama hacia el alba, Edit. E1 Universal, Lima, 1940.

HERNANDEZ, Arturo, Sangatima, Lima, 1939.

ROMERo, Fernando, 12 novelas de la selva, Lima, Edit. C. I. P., 1934.

REYNA, Ernesto, Fitzcartald, el tey del caucho, Lima, 1942.

MEdina PINON, Hernán, Esquifes de la tarde (poesía), Iquitos, 1939.

Chocano, José S., Alma América, Madrid, 1906.

Garrido Malaver, Julio, Sierra, costa, selva (poesía), Lima, 1943. 